\title{
A small volume, short-incubation-time method for measure- ment of photosynthesis as a function of incident irradiance
}

\author{
Marlon R. Lewis ${ }^{1,2}$ and John C. Smith ${ }^{2}$ \\ ' Department of Biology, Dalhousie University, Halifax, Nova Scotia, Canada B3H 4J1 \\ ${ }^{2}$ Marine Ecology Laboratory, Bedford Institute of Oceanography, Dartmouth, Nova Scotia, Canada B2Y 4A2
}

\begin{abstract}
A method is presented for the determination of algal photosynthetic rate as a function of incident irradiance. The method uses small volumes $(1 \mathrm{ml})$, short incubation times (20 min) and provides sufficient data (36 pairs) for objective analysis. Data from laboratory and natural algal populations are used to illustrate application with particular attention to the response of parameters of photosynthesis-irradiance relationships to short time-scale variations in incident irradiance such as might be experienced in a mixing water column.
\end{abstract}

The relationship between photosynthesis and incident irradiance is fundamental to the study of phytoplankton ecology and to simulation models of ecological dynamics in aquatic environments. The magnitudes of the parameters describing the photosynthesis versus irradiance curve (P-I curve) contain information on the physiology of the algae (e.g. Jassby and Platt, 1976; Platt and Jassby, 1976) and variations in the parameters can be accounted for by variations in environmental conditions (MacCaull and Platt, 1977; Harrison and Platt, 1980; Demers and Legendre, 1981; Falkowski, 1981; Malone and Neale, 1981).

The relationship between irradiance and photosynthesis for particular algal cells is not fixed: rather, the photosynthetic response will adjust according to fluctuations in ambient irradiance experienced by the cells with the passage of time. One manifestation of algal adaptation to light is variation in the parameters of P-I curves (e.g. Steemann-Nielsen and Jørgensen, 1968; Beardall and Morris, 1976; Falkowski, 1980). Such adaptive responses are ecologically important because of the inherent non-linearity in the photosynthesisirradiance relationship (Platt et al., 1977; Woods and Onken, 1982).

Usually, in the measurement of photosynthesis as a function of light, samples are exposed to a gradient of light intensity for a fixed incubation time, typically 3 to
$4 \mathrm{~h}$. The ecological interpretation of these data is severely constrained for those adaptive processes occurring on time scales of the same order or shorter than the incubation time. There is growing evidence (Harris, 1980; Demers and Legendre, 1981; Rivkin et al., 1982; Auclair et al., 1982; Gallegos et al., in press; Lewis et al., submitted) that phytoplankton effect significant photoadaptive responses with characteristic times much shorter than $4 \mathrm{~h}$ and it would be somewhat unusual for phytoplankton to experience constant irradiance throughout a $4 \mathrm{~h}$ period as they circulate in the vertical environment.

We found it necessary to consider an altemative measurement technique to circumvent some of these difficulties in the investigation of the amplitudes and time-scales associated with responses of algae to light fluctuations with time scales less than ca. $5 \mathrm{~h}$ (such as might be experienced in a mixing water column). We therefore developed, and report here, a method for measurement of algal photosynthesis as a function of light that uses short incubation times (20 min), small volumes (1 ml), short post-incubation processing times $(<1 \mathrm{~min})$ and which yields sufficient data (36 pairs) to permit objective curve fitting by minimization of residual variance about some model equation (Gallegos and Platt, 1981).

The method is a modification of the 'acid-bubbling' technique of Schindler et al. (1972). One ml of algal suspension is exposed to various light intensities with ${ }^{14} \mathrm{C}$ in glass scintillation vials illuminated from below. At the end of incubation, acid is added to the sample with shaking to purge inorganic carbon, the solution is neutralized and the scintillation fluor is added directly. The method thus does not discriminate fixation into particulate and dissolved phases.

Apparatus. The incubation chamber is depicted in Fig. 1. Although it was primarily designed as a labora- 
tory instrument, it is durable and has been used at sea in the Arctic. Two reversed flow cuvettes on the bottom are connected to cooling water and attenuate most of the infrared radiation. The sample chamber is flushed

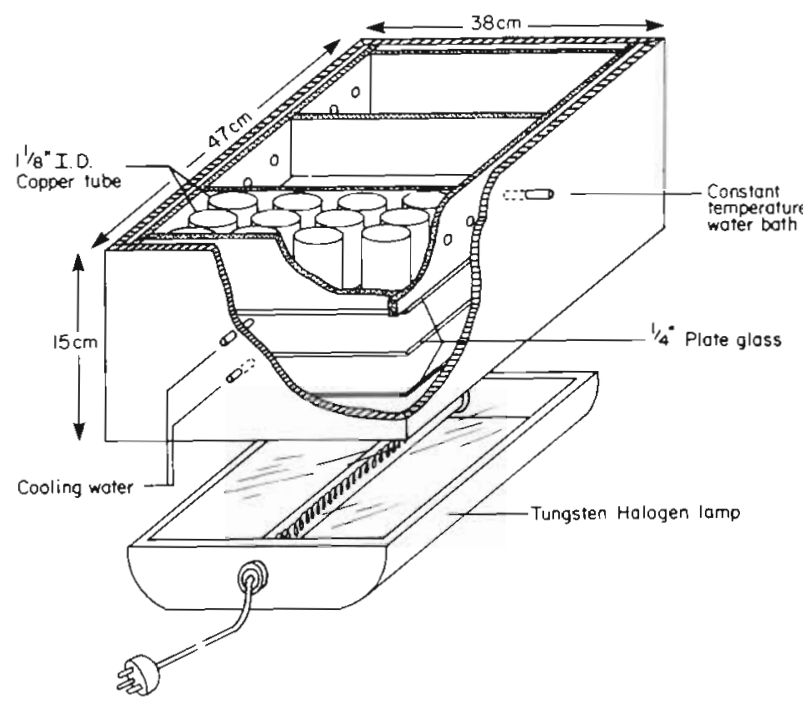

Fig. 1. Schematic diagram of incubation chamber (not to scale)

$$
\text { 은 }
$$$$
\mu \text { Einsteins } \mathrm{m}^{-2} \mathrm{~s}^{-1}
$$

600

1200 1800

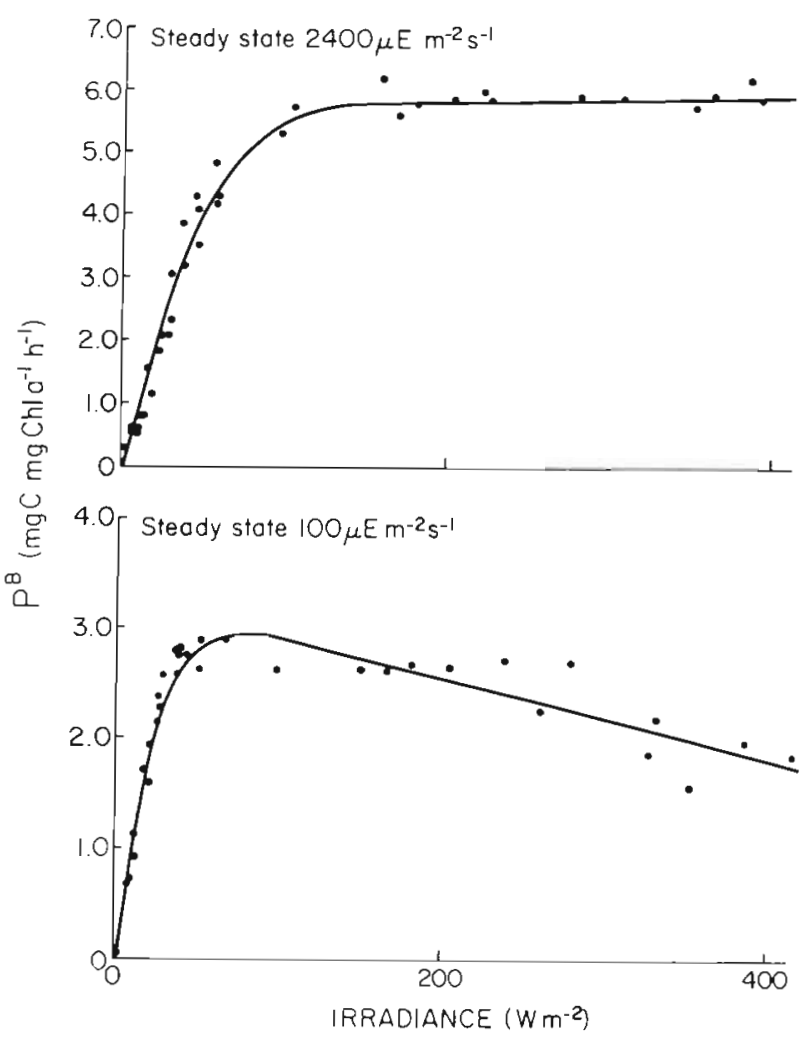

Fig. 2. Photosynthesis versus incident irradiance for 2 cultures of Thalassiosira pseudonana(3H), grown at $2400 \mu$ Einst $\mathrm{m}^{-2} \mathrm{~s}^{-1}$ and $100 \mu$ Einst $\mathrm{m}^{-2} \mathrm{~s}^{-1}$ at a high rate from a constant temperature water bath $\left( \pm 0.2 C^{\circ}\right)$. Copper sample tubes with an inner diameter equivalent to the outer diameter of scintillation vials have various grades of neutral density filters (Perforated Products) cemented to their bottoms to give a range of incident irradiance from $\sim 1$ to $2000 \mu$ Einst $\mathrm{m}^{-2} \mathrm{~s}^{-1}$. The light source is a $2000 \mathrm{~W}$ tungsten halogen lamp (Atlas Model OHS 200).

Method. Fifty $\mathrm{ml}$ of algal culture (or water sample) were placed in a beaker and ${ }^{14} \mathrm{C}$ added with stirring. With cultures, the specific activity was $\sim 0.5 \mu \mathrm{Ci} \mathrm{m} l^{-1}$; for field samples (with chlorophyll concentrations as low as $0.5 \mu \mathrm{g} \mathrm{Chl} \mathrm{a}^{-1}$ ) we used up to $5 \mu \mathrm{Ci} \mathrm{ml}^{-1}$. After thorough mixing, three $50 \mu$ l aliquots were removed to $12 \mathrm{ml}$ Aquasol (to which $20 \mu \mathrm{l} 6 \mathrm{~N} \mathrm{NaOH}$ had been added; Iverson et al., 1976) for the determination of total activity. No losses of inorganic carbon due to atmospheric exchange over the incubation period were measured. One ml aliquots were then dispensed by repetitive pipetting into the 36 scintillation vials that were in place in the Photosynthetron. In addition to the 36 samples, 3 more were taken for a time-zero control; these are immediately acidified.

The lights are controlled by a timer. At the end of a 20 min incubation, the samples were removed immediately to a tray, placed on a shaker table in a hood and acidified with $0.5 \mathrm{ml} 6 \mathrm{~N} \mathrm{HCl}$. Less acid would probably be sufficient. The vials were then shaken for $\sim 1 \mathrm{~h}$. The efficiency of inorganic $\mathrm{C}$ removal is $99 \%$ after $10 \mathrm{~min}$ with this method and $\sim 100 \%$ after $30 \mathrm{~min}$. The samples were then neutralized with $0.5 \mathrm{ml}$ $6 \mathrm{~N} \mathrm{NaOH}$ and $12 \mathrm{ml}$ of Aquasol $+10 \%$ methanol added directly to the vials. The methanol aids in the accommodation of the aqueous sample and no decrease in counting efficiencies has been noted. The time-zero controls were treated identically except that they were acidified at the beginning of the incubation.

Irradiance measurements were made with a Biospherical Instrument $4 \pi$ collector placed inside a scintillation vial. The equation of Steemann-Nielsen (1952) was used to convert $\mathrm{dpm}$ to $\mathrm{mg} \mathrm{C} \mathrm{mg} \mathrm{Chl}^{-1} \mathrm{~h}^{-1}$ (after substraction of the time-zero control) and the data fitted by a non-linear parameter estimation routine (Bard, 1974) to the following photosynthesis-irradiance model (Platt et al., 1980):

$$
\mathrm{P}^{\mathrm{B}}(\mathrm{I})=\mathrm{P}_{\mathrm{s}}^{\mathrm{B}}\left[1-\exp \left(-\alpha \mathrm{I} / \mathrm{P}_{\mathrm{s}}^{\mathrm{B}}\right)\right] \exp \left(-\beta \mathrm{J} / \mathrm{P}_{\mathrm{s}}^{\mathrm{B}}\right)
$$

where $\alpha=$ slope of the curve as I goes to zero; $\beta=\mathrm{a}$ parameter defining the degree of inhibition at high intensities. $\mathrm{P}_{\mathrm{s}}^{\mathrm{B}}=$ potential maximum photosynthetic rate normalized to chlorophyll; it is equal to the observed maximum rate, $\mathrm{P}_{\mathrm{m}}^{\mathrm{B}}$, if there is no inhibition. $\mathrm{P}_{\mathrm{s}}^{\mathrm{B}}$ and $\mathrm{P}_{\mathrm{m}}^{\mathrm{B}}$ are related by the following

$$
\mathrm{P}_{\mathrm{m}}^{\mathrm{B}}=\mathrm{P}_{\mathrm{s}}^{\mathrm{B}}\left(\frac{\alpha}{\alpha+\beta}\right)\left(\frac{\beta}{\alpha+\beta}\right)^{\beta / \alpha}
$$


Results and discussion. Precision of the method is reflected in an average ( $>75$ experiments) coefficient of variation for a single experiment of $4.3 \%$ for $\mathrm{P}_{\mathrm{m}}^{\mathrm{B}}$ $7.0 \%$ for $\alpha$, and $37.3 \%$ for $\beta$. Some typical examples of the resolution of the method are seen in Fig. 2. Both experiments were done on laboratory cultures of Thalassiosira pseudonana (Clone $3 \mathrm{H}$ ). In one case, the algae were grown at $2400 \mu$ Einst $\mathrm{m}^{-2} \mathrm{~s}^{-1}$ continuous light (Fig. 2 A) while in the other, they were grown at $100 \mu$ Einst $\mathrm{m}^{-2} \mathrm{~s}^{-1}$ (Fig. $2 \mathrm{~B}$ ). The time scales associated with changes in the parameters upon shift up $\left(100 \mu\right.$ Einst $\mathrm{m}^{-2} \mathrm{~s}^{-1}$ culture transfered to $2400 \mu$ Einst $\mathrm{m}^{-2} \mathrm{~s}^{-1}$ ) differs for each of the parameters (Figs. 3 and 4) but it is clear that significant adaptation takes place over the time scale associated with incubations of more standard length.

The method has proven useful in extensive experiments on natural populations as well. On many occasions we compared 20 min incubations with P-I curves generated from longer, more standard incubations (Jassby and Platt, 1976): one is presented here for which the chlorophyll concentration was $0.5 \mu \mathrm{g} \mathrm{l}^{-1}$ (Fig. 5). Lower phytoplankton densities may require

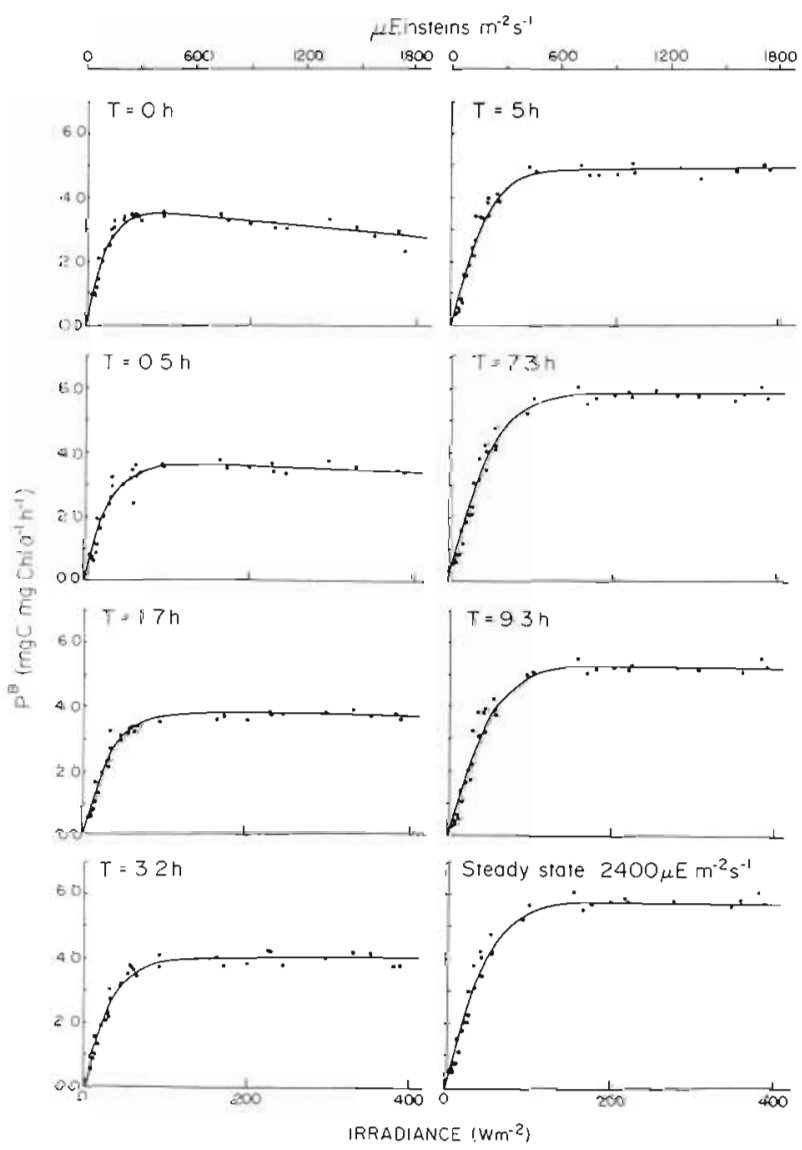

Fig. 3. Time course of photosynthesis versus irradiance for a culture of Thalassiosira pseudonanea(3H) after a switch from a culture irradiance of $100 \mu$ Einst $\mathrm{m}^{-2} \mathrm{~s}^{-1}$ to $2400 \mu$ Einst $\mathrm{m}^{-2} \mathrm{~s}^{-1}$
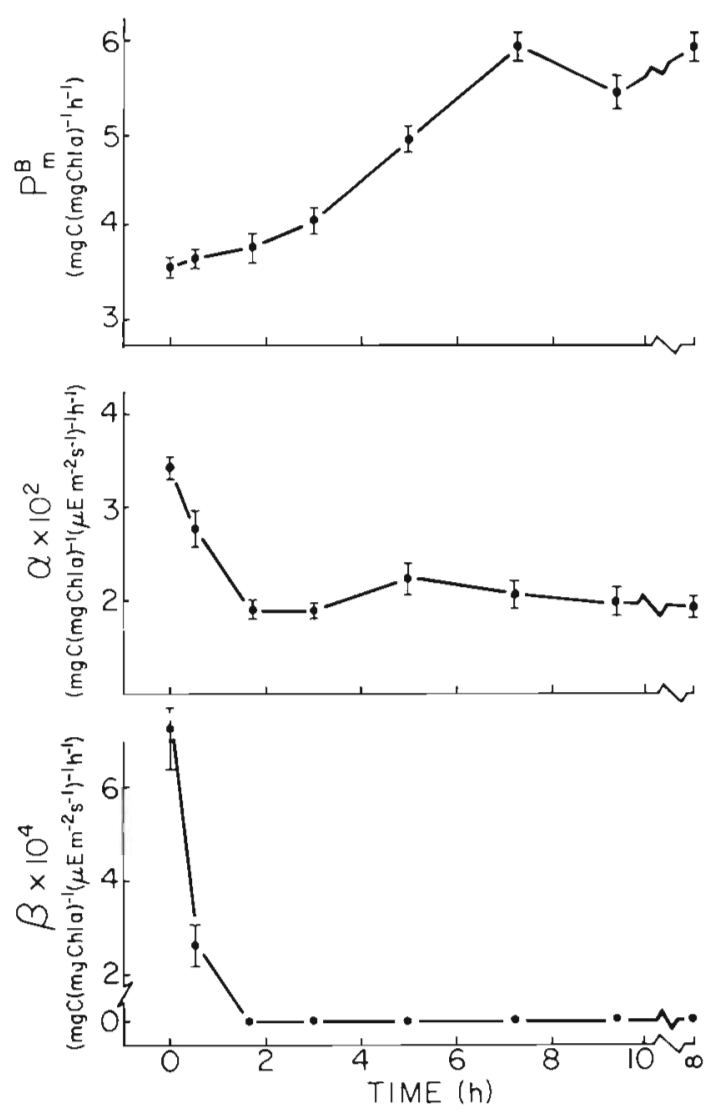

Fig. 4. Variation in the parameters of the photosynthesis irradiance curves in Fig. $3 . \infty$ refers to steady-state $1>20$ generations) value

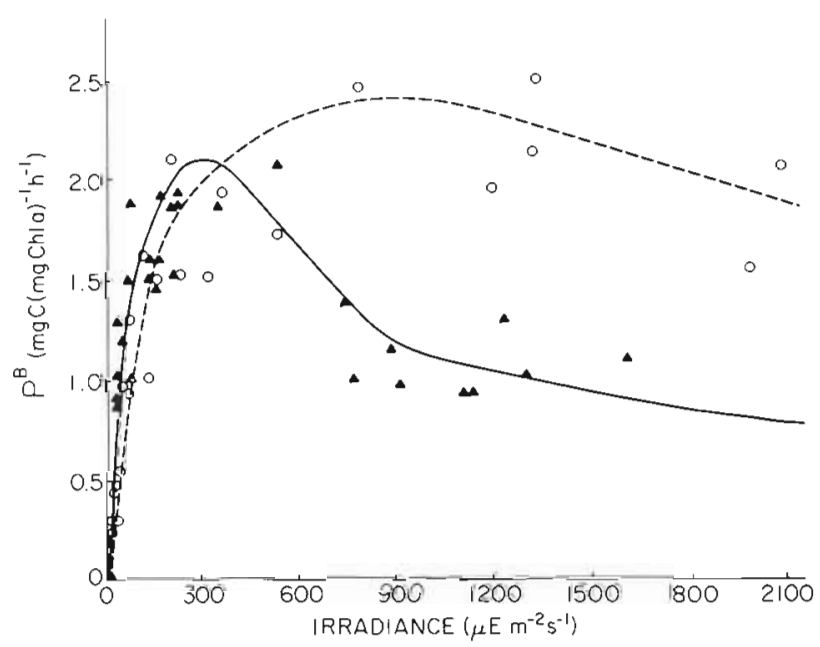

Fig. 5. Photosynthesis versus irradiance curves for the same natural phytoplankton sample incubated for $3 \mathrm{~h}$ (circles) and for $20 \mathrm{~min}$ in the new incubation chamber (triangles)

more isotope, but there does not seem to be any reason why samples with phytoplankton concentrations more typical of the open ocean might not be accessible to measurement, unless the added carbon were high enough to perturb the carbon content of the sample. 
Differences between the $3 \mathrm{~h}$ incubation and the $20 \mathrm{~min}$ incubation are consistent with the adaptation patterns in the laboratory population (Fig. 4).

We have presented here a small volume, short-incubation-time method for the determination of the relationship between photosynthesis and irradiance. It is relatively rapid and one operator can complete the experiment in $\sim 0.5 \mathrm{~h}$. The method has proven useful both in the laboratory and in the field for the analysis of short time scale response of algae to changes in available light.

Acknowledgements. We would like to thank Trevor Platt, Chuck Gallegos, William Li, W. Glen Harrison and John Cullen for discussions of the method and are indebted to Brian Irwin for discussions and his assistance. MRL was supported by the National Sciences and Engineering Research Council of Canada and by a Dalhousie University Fellowship.

\section{LITERATURE CITED}

Auclair, J. C., Demers, S., Frechette, M., Legendre, L., Trump, C. L. (1982). High frequency endogenous periodicities of chlorophyll synthesis in estuarine phytoplankton. Limnol. Oceanogr. 27: 348-352

Bard, Y. (1974). Nonlinear parameter estimation. Academic Press, New York

BeardaII, J., Morris, I. (1976). The concept of light intensity adaptation in marine phytoplankton: some experiments with Phaeodactylum tricornutum. Mar. Biol. 37: 377-387

Demers, S., Legendre, L. (1981). Melange vertical et capacite photosynthetique du phytoplancton estuarien (estuaire du Saint-Laurent). Mar. Biol, 64: 243-250

Falkowski, P. G. (1980). Light-shade adaptation in marine phytoplankton. In: Falkowski, P. G. (ed.) Primary productivity in the sea. Plenum Press, New York, p. 99-119

Falkowski, P. G. (1981). Light-shade adaptation and assimilation numbers. J. Plankton Res. 3: 203-216

Gallegos, C. L., Platt, T. (1981). Photosynthesis measurements on natural populations of phytoplankton: numerical analysis. In: Platt, $T$ (ed.) Physiological bases of phytoplankton ecology. Can. Bull. Fish. Aquat. Sci. 210: 103-112

Gallegos, C. L., Platt, T., Harrison, W. G., Irwin, B. Photosynthetic parameters of arctic marine phytoplankton: vertical variations and time-scales of adaptation. Limnol. Oceanogr., submitted

Harris, G. P. (1980). Temporal and spatial scales in phyto- plankton ecology. Mechanisms, methods, models, and management. Can. J. Fish. Aquat. Sci. 37: 877-900

Harrison, W. G., Platt, T. (1980). Variations in assimilation number of coastal marine phytoplankton: effects of environmental co-variates. J. Plankton Res. 2: 249-260

Iverson, R. L., Bittaker, H. F., Myers, V. B. (1976). Loss of radiocarbon in direct use of Aquasol for liquid scintillation counting of solutions containing ${ }^{14} \mathrm{C}-\mathrm{NaHCO}$. Limnol. Oceanogr 21: 756-758

Jassby, A. D., Platt, T. (1976). Mathematical formulation of the relationship between photosynthesis and light for phytoplankton. Limnol. Oceanogr. 21: 540-547

Lewis, M. R., Cullen, J. J., Platt, T. Relationships between vertical mixing and photoadaptation of phytoplankton similarity criteria. Mar. Ecol. Prog. Ser., submitted

MacCaull, W. A., Platt, T. (1977). Diel variations in the photosynthetic parameters of coastal marine phytoplankton. Limnol. Oceanogr. 22: 723-731

Malone, T C., Neale, J. P. (1981). Parameters of light-dependent photosynthesis for phytoplankton size fractions in temperate estuarine and coastal environments. Mar. Biol. 61: $289-297$

Platt, T., Jassby, A. D. (1976). The relationship between photosynthesis and light for natural assemblages of coastal marine phytoplankton. J. Phycol. 12: 421-430

Platt, T., Gallegos, C. L., Harrison, W. G. (1980). Photoinhibition of photosynthesis in natural assemblages of marine phytoplankton. J. mar. Res. 38: 687-701

Platt, T., Denman, K. L., Jassby, A. D. (1977). Modeling the productivity of phytoplankton. In: Goldberg, E. D. (ed.) The sea, Vol. VI. John Wiley, New York, p. 807-856

Platt, T., Harrison, W. G., Irwin, B., Horne, E. P., Gallegos, C. L. (in press). Photosynthesis and photoadaptation of marine phytoplankton in the Arctic. Deep Sea Res.

Rivkin, R. B., Seliger, H. H., Swift, E., Biggley, W. H. (1982). Light-shade adaptation by the oceanic dinoflagellates Pyrocystis noctiluca and P. fusiformis. Mar. Biol. 68: 181-191

Schindler, D. W., Schmidt, R. V., Reid, R. A. (1972). Acidification and bubbling as an alternative to filtration in determining phytoplankton production by the ${ }^{14} \mathrm{C}$ method. $\mathrm{J}$. Fish. Res. Bd Can. 29: 1627-1631

Steemann-Nielsen, E. (1952). The use of radioactive carbon $\left({ }^{14} \mathrm{C}\right)$ for measuring organic production in the sea. J. Cons. perm. int. Explor. Mer 18: 117-140

Steemann-Nielsen, E., Jørgensen, E. G. (1968). The adaptation of plankton algae III. With special consideration of the importance in nature. Physiol. Plant. 21: 647-654

Woods, J. P., Onken, R. (1982). Diurnal variation and primary production in the ocean-preliminary results of a Lagrangian ensemble model. J. Plankton Res. 4: 735-756

Accepted for printing on April 14, 1983 